\title{
Dural sinus thrombosis with the empty delta sign
}

Trombose de seio dural com o sinal do delta vazio

Diogo Goulart Corrêa ${ }^{1,2}$, Geraldo Veloso Correia ${ }^{1}$, Rafael Silveira Borges ${ }^{1,2}$

A 43-year-old woman, presented with headache, reduced visual acuity, for 5 days and bilateral papilledema. Non-enhanced cerebral computed tomography (CT) was normal. The venous angiography-CT revealed the empty delta sign within superior sagittal, right transverse and sigmoid sinuses, characterizing sinus thrombosis (Figure). The empty delta sign is a central intraluminal filling defect, representing a thrombus surrounded by contrastenhanced dural collateral venous channels. ${ }^{1}$. It can be seen in $25 \%-75 \%$ of sinus thrombosis, using wider window settings than those used for brain parenchyma ${ }^{2}$. Most often, non-contrast CT is normal, hence the importance of using intravenous contrast when suspecting of dural thrombosis ${ }^{3}$.
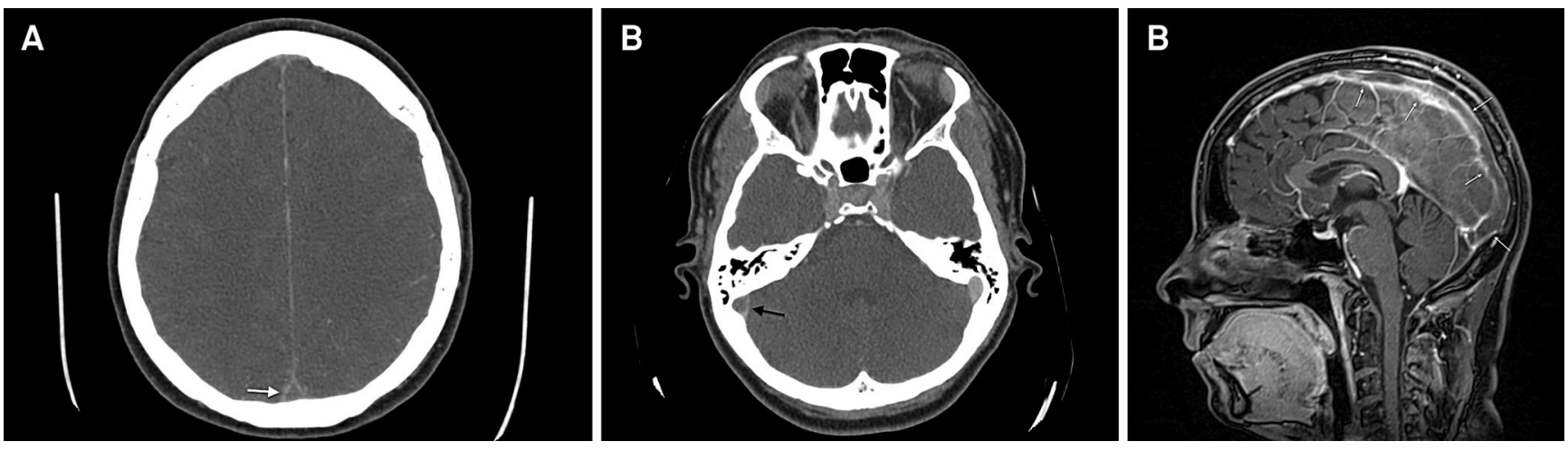

Figure. Contrast-enhanced computed tomography (A and B) shows intraluminal filling defects in sagittal sinus (white arrow in A) and transverse right sinus (black arrow in B), surrounded by contrast (the empty delta sign), characterizing right transverse and superior sagittal sinuses thrombosis. Compare the right with the left transverse sinuses, in B, to see the intraluminal filling defect. Non-enhanced computed tomography was normal (not shown). Magnetic resonance venous angiography (C) of the same patient shows a filling defect affecting almost the entire superior sagittal sinus (thin white arrows in C).

\section{References}

1. Provenzale JM, Kranz PG. Dural sinus thrombosis: sources of error in image interpretation. AJR Am J Roentgenol. 2011;196(1):23-31. http://dx.doi.org/10.2214/AJR.10.5323

2. Rodallec MH, Krainik A, Feydy A, Hélias A, Colombani JM, Jullès MC et al. Cerebral venous thrombosis and multidetector CT angiography: tips and tricks. Radiographics. 2006;26 Suppl 1:S5-18. http://dx.doi. org/10.1148/rg.26sj065505

3. Wasay M, Azeemuddin M. Neuroimaging of cerebral venous thrombosis. J Neuroimaging. 2005;15(2):118-28. http://dx.doi.org/10.1111/ j.1552-6569.2005.tb00296.x

${ }^{1}$ Hospital Casa de Portugal, Rio de Janeiro RJ, Brazil;

${ }^{2}$ Universidade Federal do Rio de Janeiro, Rio de Janeiro RJ, Brazil.

Correspondence: Diogo Goulart Corrêa; Rua Duquesa de Bragança, 85 / ap. 109; 20540-300 Rio de Janeiro RJ, Brasil; E-mail: diegogoulartcorrea@yahoo.com.br Support: Hospital Casa de Portugal

Conflict of interest: There is no conflict of interest to declare.

Received 08 May 2014; Received in final form 25 July 2014; Accepted 14 August 2014. 